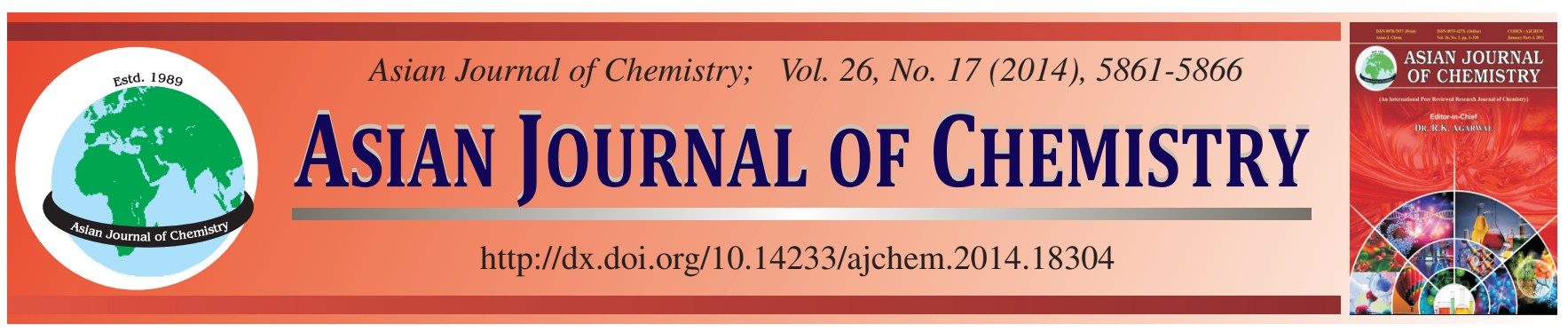

\title{
Comparison and Analysis on Moisture Absorption Performances of Pineapple Leaf Fiber and Other Plant Fibers $\dagger$
}

\author{
Wenwei Lian, Jin Zhang ${ }^{*}$, Zhong Xue, Mingfu Li and Tao Huang
}

Tropical Agricultural Machinery Research Institute, Chinese Academy of Tropical Agricultural Sciences, Zhanjiang, P.R. China

*Corresponding author: Fax: +86 759 2859264; Tel: +86 759 2859234; E-mail: khuangtao@163.com

Scanning electron microscopy, X-ray diffraction and other test methods were used to examine the microcosmic morphologies of pineapple leaf fiber and fibers of flax, ramie and cotton. Test results showed that the pineapple leaf fiber's morphological structure is different from the other three's because of its larger specific surface area. Pineapple leaf fiber's crystallinity is close to those of flax fiber and ramie fiber and higher than that of cotton fiber. Under standard tropical conditions, oven dryer and regression model were used to test and analyze the four fibers' moisture absorption and desorption performances. Test results also showed that pineapple leaf fiber's moisture absorption performance is the highest and cotton's is the lowest. Pineapple leaf fiber's moisture regain rate after reaching moisture absorption equilibrium and moisture absorption rate were close to flax fiber and ramie fiber's and its moisture regain rate after moisture desorption equilibrium and moisture desorption rate were higher than those of flax and ramie.

Keywords: Pineapple leaf fiber, Morphological structure, Moisture absorption performance.

\section{INTRODUCTION}

Pineapple leaf fiber is a tropical plant fiber which is extracted from pineapple leaves and belongs to leaf fiber category. Pineapple leaf fiber is white in colour, feels soft and smooth as silk, so it is also called "pineapple leaf silk". Pineapple leaf fiber's properties such as chemical properties, physical properties and mechanical properties, etc., are similar to those of flax, ramie and hemp fibers ${ }^{1-4}$. In terms of spinnability, pineapple leaf fiber, due to its too short single fiber, cannot be spun directly. So like flax fiber and hemp fiber, it is processed by semi-degumming method to ensure that a certain amount of gum is retained on the fiber which bonds the very short single fibers together to form long fibers to meet the yarning requirements ${ }^{5,6}$. Pineapple leaf fiber owns good moisture absorption and desorption performances which are very similar to those of flax fiber ${ }^{1-7}$. So far, some studies on pineapple leaf fiber's structure, properties and spinnability etc. ${ }^{8-11}$ have been conducted by Chinese researchers, but pineapple leaf fiber' moisture absorption was rarely studied and reported. It is known through experiences during using it rather than through specific scientific data that pineapple leaf fiber owns very good moisture absorption and desorption performances $^{12}$. Fiber's moisture absorption is a key charac- teristic indicator affecting fiber's spinning, dyeing and finishing and textile comfort evaluation ${ }^{13}$. Pineapple leaf fiber's structure and moisture absorption performance need to be known better for people to adjust the processing technologies easily and better control pineapple leaf fiber's moisture absorption and desorption behaviours and thermal-wet comfort according to needs in actual production and increase the added value of pineapple leaf fiber's textile. Therefore, main structures and moisture absorption performances of pineapple leaf fiber, flax, ramie and cotton were tested and compared and analysis was made on pineapple leaf fiber's structural characteristics and moisture absorption performance.

\section{EXPERIMENTAL}

Test material: The pineapple leaf fiber used in the test was semi-degummed, the flax fiber was degummed with retting of warm water immersion method and the ramie fiber and longstaple cotton fiber were provided by Anhui Tongling Hemp Industry Co., Ltd. All the fibers were cut by a fiber amputator and their specifications are as shown in Table-1.

Test instrument: S-4800 scanning electron microscope (SEM) made by Hitachi, Japan; D/Max-III automatic X-ray diffractometer by Rigaku, Japan; YG747 eight-basket constant- 


\begin{tabular}{ccc}
\hline \multicolumn{3}{c}{ TABLE-1 } \\
FIBER SPECIFICATIONS \\
\hline Description & Length $(\mathrm{mm})$ & Finess $(\mathrm{Nm})$ \\
\hline Pineapple leaf fiber & 30 & 730 \\
Flax fiber & 30 & 2330 \\
Ramie fiber & 30 & 2158 \\
Cotton fiber & 30 & 6850 \\
\hline
\end{tabular}

temperature fast-drying oven made by Nantong Sansi Electromechanical Science and Technology Co., Ltd.; YG501D moisture permeability test chamber made by Shanghai Lichi Measuring Instrument Co., Ltd.; electronic balance (with a precision of $0.000 \mathrm{~g}$ ); glass dryer; glass vessels; and sealed weighing boxes, etc.

Morphology observation: Longitudinal surface morphology: Fiber sample was spread on the sample stage. After fiber was vacuum sputter-plated, the S-4800 scanning electron microscope was used to observe viscose fiber's surface morphology.

Cross-sectional surface morphology: Fiber sample was sliced and fixed on the sample stage. After fiber was vacuum sputter-plated, the S-4800 scanning electron microscope was used to observe fiber's cross-sectional morphology.

X-Ray diffraction analysis: D/Max-III automatic X-ray diffractometer from Rigaku, Japan and powder method were adopted for the test. Test conditions: $\mathrm{CuK}_{\alpha}$ target with a ray wavelength $\lambda=0.154 \mathrm{~nm} ; 35 \mathrm{kV}$ voltage; $25 \mathrm{~mA}$ current; linked-scanning with a diffraction direction of $\theta-2 \theta$ and a rotated half-cone angle $2 \theta$ of $5-40^{\circ}$.

Performance test: According to Chinese national standards GB/T9995-1997 "Determination of Textile Materials' Moisture Content and Moisture Regain Rate" and GB65291986 "Standard Atmosphere for Textile Humidification and Test", oven drying method was adopted to test fibers' moisture absorption and desorption performances.

Moisture absorption test: About $1 \mathrm{~g}$ of fiber sample was taken and placed in an oven to dry at $40-50{ }^{\circ} \mathrm{C}$ for $1 \mathrm{~h}$ to reduce fiber sample's moisture regain rate. Fiber sample's initial mass was weighed. The fiber sample was placed in a glass vessel; moisture absorption test was performed while keeping it in fluffy state and the sample's mass was recorded once every 5 min until moisture absorption equilibrium reached standard condition (in tropical areas). The sample was dried in an oven at $105^{\circ} \mathrm{C}$, cooled in an airtight container and weighed for mass and then moisture regain rate was calculated.

Moisture desorption test: About $1 \mathrm{~g}$ of fiber sample was taken and placed in YG501D moisture permeability test chamber for $96 \mathrm{~h}$ in a relative humidity of $100 \%$ for the sample to absorb moisture fully. Moisture desorption test was performed in standard condition (tropical) and fiber sample's masses were recorded once every five minutes. After reaching moisture desorption equilibrium, the sample was dried, cooled in an airtight state and weighed for mass and moisture regain rate was calculated.

Data processing: Based on the above test data, SAS software was used to study the correlation between fiber's moisture regain rate and time. Regression analysis was performed on the correlation between fiber's moisture regain rate and its moisture absorption and desorption rates.

\section{RESULTS AND DISCUSSION}

Fiber morphology: The SEM photos of pineapple leaf fiber, flax fiber, ramie fiber and cotton fiber's cross-sectional and longitudinal surface morphologies are as shown in Fig. 1, from which microcosmic morphologies of the fibers can be seen. And analysis on their morphologies is shown in Table-2.
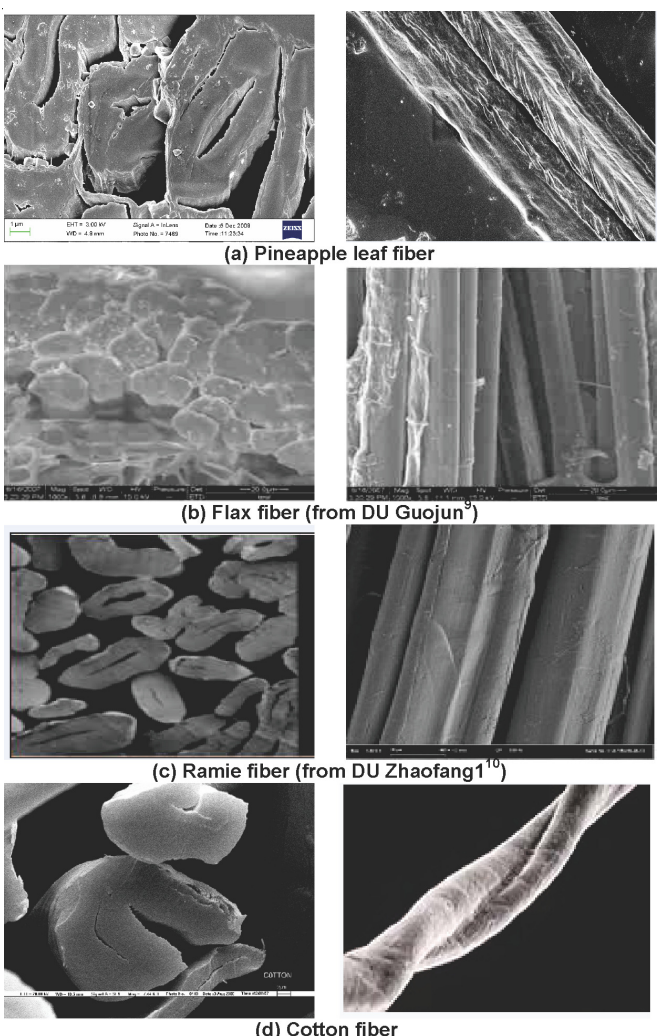

(d) Cotton fiber

Fig. 1. Four fibers' cross-sectional and longitudinal surface morphologies

TABLE-2

\section{ANALYSIS ON FOUR FIBERS' MORPHOLOGIES}

\begin{tabular}{|c|c|c|}
\hline Fiber & Cross-sectional morphologies & Longitudinal surface morphologies \\
\hline Pineapple leaf fiber & $\begin{array}{l}\text { Its single fiber looks ovoid and polygonal with thick cell } \\
\text { walls and lumen. Fiber bundle is composed of single fibers } \\
\text { and large gap exists between single fibers }{ }^{8} \text {. }\end{array}$ & $\begin{array}{l}\text { Fiber surface looks rough with longitudinal cracks but } \\
\text { without natural distortion }{ }^{8} \text {. }\end{array}$ \\
\hline Flax fiber & $\begin{array}{l}\text { Its fiber looks oblate or round with thick cell walls, many } \\
\text { layers and lumen }{ }^{9-12} \text {. }\end{array}$ & $\begin{array}{l}\text { Fiber surface looks smooth with uniform thicknesses and } \\
\text { clear bamboo-like joints but without natural distortion }{ }^{9-12} \text {. }\end{array}$ \\
\hline Ramie fiber & $\begin{array}{l}\text { Its fiber looks waist-round and polygonal with lumen. } \\
\text { Cracks exist between lumen and cell wall }{ }^{10} \text {. }\end{array}$ & $\begin{array}{l}\text { Fiber surface looks smooth with non-uniform thicknesses, } \\
\text { appears cylindrical or likes a flat belt without obvious } \\
\text { natural distortion }{ }^{10-13} \text {. }\end{array}$ \\
\hline Cotton fiber & Its fiber looks irregular waist-round with lumen ${ }^{13}$. & $\begin{array}{l}\text { Fibers are spirally twisted in an irregular way along fibers' } \\
\text { length with ever-changing direction }{ }^{13} \text {. }\end{array}$ \\
\hline
\end{tabular}


X-Ray diffraction analysis: Pineapple leaf fiber, flax fiber, ramie fiber and cotton fiber are natural polymers which are either partially crystalline or non-crystalline in structure. Crystallinity can tell the weight or volume ratios between crystalline and non-crystalline structures directly. Applying X-ray diffractometer to test these fibers and based on the characteristic diffraction peaks in their spectra, crystal fibers' types can be determined and fibers' crystallinities can also be estimated, which are expressed in X-ray crystallographic index. Due to the fact that large molecules are arranged in a tidy and dense way within fibers' crystallization zone and fewer holes exist between slots, binding forces of the neighboring radicals between molecules are fully saturated and moisture absorption ability in fiber crystallization zone is very low; while in noncrystallization zone, large molecules are arranged in a more disorder way, more slots and holes exist with low density, distances between large molecules' radicals are larger, binding forces are smaller and not fully saturated, so fibers' moisture absorption ability in non-crystallization zone is higher. Therefore, the lower the fiber crystallinity is, the higher its moisture absorption abiliity is ${ }^{13}$. According to the test results shown in Table-3, the crystallinity of pineapple leaf fiber, flax fiber and ramie fiber are $70.63,67.43$ and $72.02 \%$, respectively with a difference of $\pm 3 \%$, which shows that the sizes of their amorphous area and moisture absorption area are similar.

\begin{tabular}{|c|c|c|c|c|}
\hline \multicolumn{5}{|c|}{$\begin{array}{c}\text { TABLE-3 } \\
\text { X-RAY DIFFRACTION RESULTS OF PINEAPPLE LEAF FIBER, } \\
\text { FLAX FIBER, RAMIE FIBER AND COTTON FIBER }\end{array}$} \\
\hline Fiber & $\begin{array}{l}\text { Crystal } \\
\text { face }\end{array}$ & $2 \theta\left({ }^{\circ}\right)$ & $\begin{array}{l}\text { Distance between } \\
\text { crystal face }(\mathrm{d} / \mathrm{nm})\end{array}$ & $\begin{array}{c}\text { Crystallinity } \\
(\mathrm{X} / \%)\end{array}$ \\
\hline \multirow{3}{*}{$\begin{array}{l}\text { Pineapple } \\
\text { leaf fiber }\end{array}$} & $(101)$ & 14.60 & 0.6109 & \multirow{3}{*}{70.63} \\
\hline & $(10 \overline{1})$ & 16.70 & 0.5359 & \\
\hline & (102) & 22.50 & 0.4024 & \\
\hline \multirow{3}{*}{ Flax fiber } & (101) & 14.70 & 0.6069 & \multirow{3}{*}{67.43} \\
\hline & $(10 \overline{1})$ & 16.50 & 0.5422 & \\
\hline & (102) & 22.50 & 0.4024 & \\
\hline \multirow{3}{*}{$\begin{array}{l}\text { Ramie } \\
\text { fiber }\end{array}$} & $(101)$ & 15.10 & 0.5912 & \multirow{3}{*}{72.02} \\
\hline & $(10 \overline{1})$ & 16.40 & 0.5454 & \\
\hline & (102) & 22.70 & 0.3991 & \\
\hline \multirow{3}{*}{$\begin{array}{l}\text { Cotton } \\
\text { fiber }\end{array}$} & $(101)$ & 14.70 & 0.6069 & \multirow{3}{*}{64.43} \\
\hline & $(10 \overline{1})$ & 16.30 & 0.5487 & \\
\hline & (102) & 22.80 & 0.3974 & \\
\hline
\end{tabular}

Moisture absorption and desorption performance analysis: Four fibers' moisture absorption curves are shown in Fig. 2(a), from which it can be seen that these fibers' moisture absorption curves are similar and moisture absorption equilibrium was reached after around 60-120 min. In the initial stage of moisture absorption, flax fiber's moisture absorption rate was the highest and kept higher than those of the other three fibers; ramie fiber's moisture absorption rate was slightly higher than pineapple leaf fiber's and cotton fiber's was the lowest. Fiber moisture regain rates slowed down gradually with moisture absorption time and moisture absorption equilibrium was reached after $2 \mathrm{~h}$. At moisture absorption equilibrium, the moisture regain rates of flax fiber, ramie fiber, cotton fiber and pineapple leaf fiber were 16.59, 16.16, 16.04 and $13.33 \%$, respectively. Four fibers' moisture desorption curves are shown in Fig. 2(b), from which it can be seen that the four fibers'

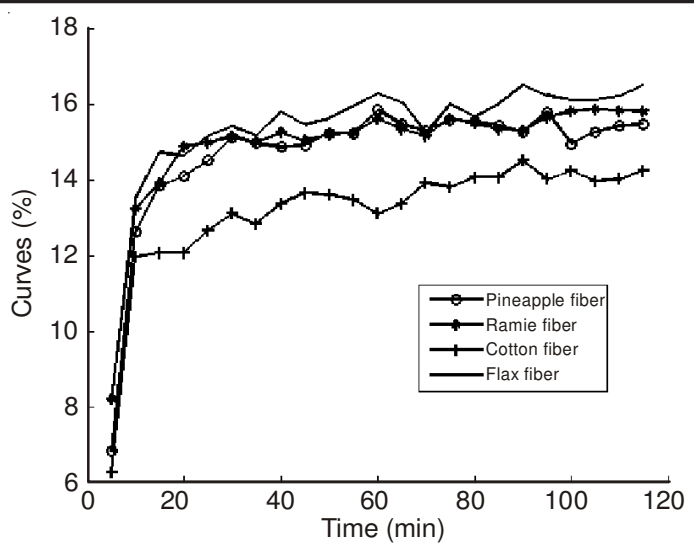

(a) Moisture absorption

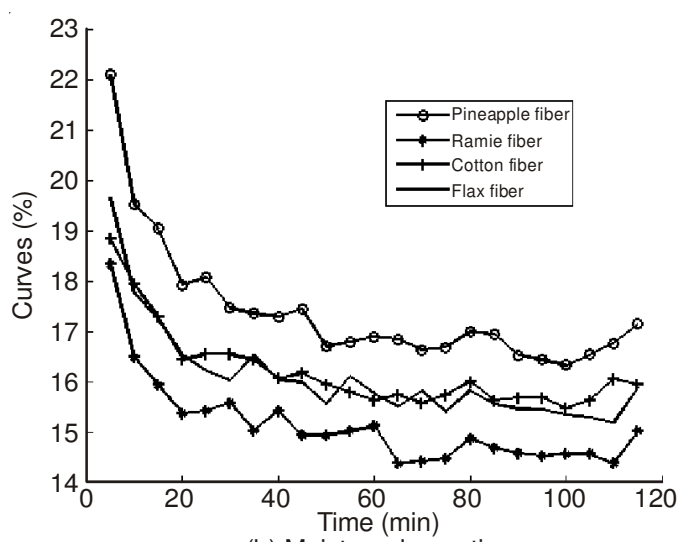

(b) Moisture desorption

Fig. 2. Moisture absorption and desorption curves

moisture desorption curves are also similar with a pattern of "from fast to slow". As to the initial moisture regain rates, pineapple leaf fiber's > flax fiber's $>$ ramie fiber's $>$ cotton fiber's. Four fibers' moisture desorption equilibrium was reached after $1 \mathrm{~h}$ and at moisture desorption equilibrium, the moisture regain rates of pineapple leaf fiber, flax fiber, ramie fiber and cotton fiber were 19.53, 19.64, 19.53 and $14.95 \%$, respectively. The moisture-absorption lag values of pineapple leaf fiber, flax fiber, ramie fiber and cotton fiber were 3.60, $2.90,1.76$ and $1.62 \%$, respectively. Lag value is affected by fiber's moisture absorption performance. Generally, the higher the fiber's moisture absorption ability is, the higher the lag value will be ${ }^{13}$. So, pineapple leaf fiber's moisture absorption ability is higher than the other three fibers'.

Creation of moisture-absorption and moisture-desorption moisture regain rates' regression equations: According to the relation curves between fibers' moisture regain rate and time during moisture absorption and desorption, it can be derived from Fick equation that their theoretical curves are exponential functions. So, regression equation's general formula for the relation between moisture-absorption regain rate $\left(\mathrm{W}_{\mathrm{a}}\right)$ and moisture-desorption regain rate $\left(\mathrm{W}_{\mathrm{d}}\right)$ and time $(\mathrm{t})$ is expressed as:

$$
\mathrm{W}_{\mathrm{a}}\left(\mathrm{W}_{\mathrm{d}}\right)=\mathrm{a}+\mathrm{be}^{-\mathrm{ct}}
$$

In the above formula, $\mathrm{W}_{\mathrm{a}} / \mathrm{W}_{\mathrm{d}}$ are moisture regain rates in \%; $\mathrm{t}$ is time in minutes; $\mathrm{a}, \mathrm{b}$ and $\mathrm{c}$ are constants.

SAS software was used to fit the test data to regression curves and four fibers' regression equations for the relations 
between moisture regain rate and time during moisture absorption and desorption were obtained as follows:

$$
\begin{aligned}
& \mathrm{W}_{\mathrm{a}(\text { Pineapple-fiber })}=15.2592-20.9423 \mathrm{e}^{-0.1861 \mathrm{t}} \\
& \mathrm{W}_{\mathrm{d}(\text { Pineaple-fiber })}=16.6873+7.4639 \mathrm{e}^{-0.0779 t} \\
& \mathrm{~W}_{\mathrm{a}(\text { Flax -fiber })}=15.8511-19.7252 \mathrm{e}^{-0.1912 \mathrm{t}} \\
& \mathrm{W}_{\mathrm{d}(\text { Flax-fiber })}=15.6082+5.531 \mathrm{e}^{-0.0848 \mathrm{t}} \\
& \mathrm{W}_{\mathrm{a}(\text { Ramie-fiber })}=15.3939-18.5984 \mathrm{e}^{-0.1933 \mathrm{t}} \\
& \mathrm{W}_{\mathrm{d}(\text { Remie-fiber })}=14.6753+4.9606 \mathrm{e}^{-0.0808 \mathrm{t}} \\
& \mathrm{W}_{\mathrm{a}(\text { Cotton-fiber })}=13.6704-16.6095 \mathrm{e}^{-0.1718 \mathrm{t}} \\
& \mathrm{W}_{\mathrm{d}(\text { Cotton-fiber })}=15.7051+4.1967 \mathrm{e}^{-0.0642 \mathrm{t}}
\end{aligned}
$$

Moisture regain rates' regression curves for moisture absorption and moisture desorption are shown in Fig. 3. The variance analysis on pineapple leaf fiber's regression equations for moisture absorption and desorption is shown in Table-4, from which it can be seen that the regression results are significant.

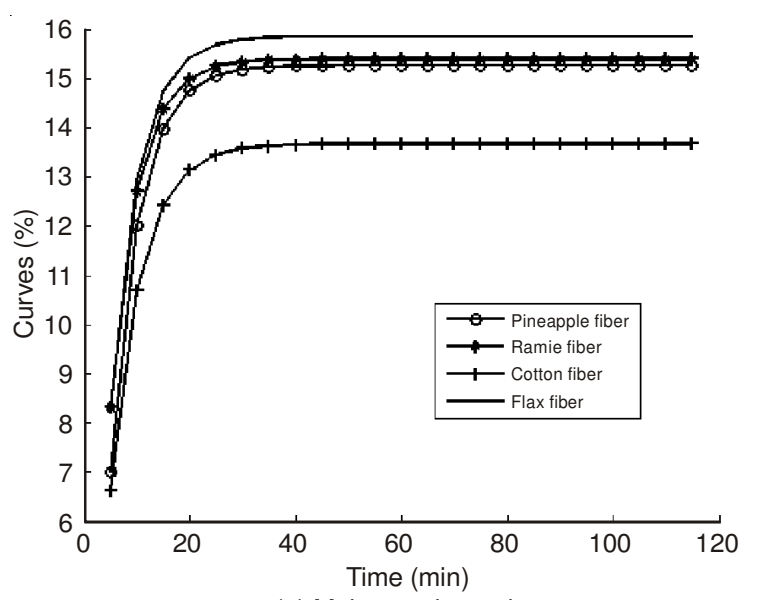

(a) Moisture absorption

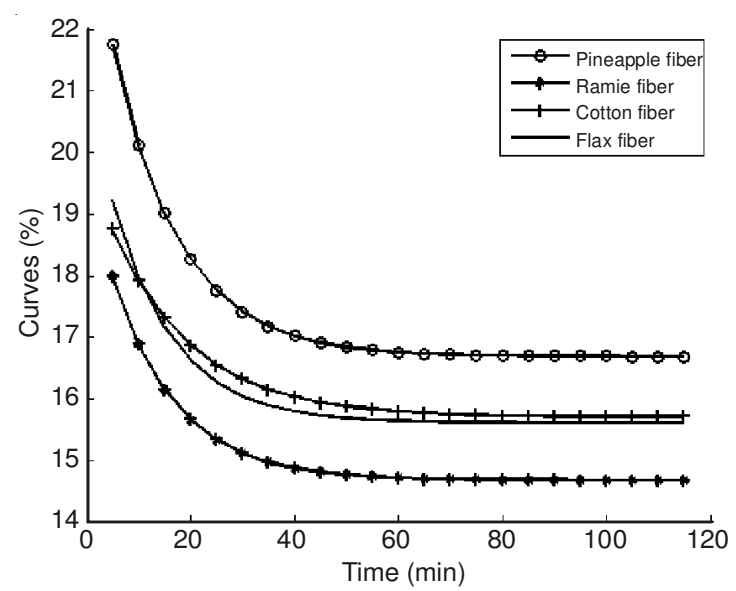

(b) Moisture desorption

Fig. 3. Moisture-absorption and moisture-desorption moisture regain rates' regression curves

Creation of moisture-absorption and moisture-desorption moisture regain rates' regression curves: From Figs. 2 and 3,

\begin{tabular}{cccccc}
\hline \multicolumn{7}{c}{ TABLE-4 } \\
\multicolumn{7}{c}{ VARIANCE ANALYSIS ON PINEAPPLE LEAF FIBER'S } \\
REGRESSION EQUATIONS FOR MOISTURE DESORPTION \\
\hline Variance & Quadratic & $\begin{array}{c}\text { Degree of } \\
\text { freedom }\end{array}$ & $\begin{array}{c}\text { Mean } \\
\text { square }\end{array}$ & F & Pr > F \\
source & sum & 2 & 36.3566 & 286.43 & $<0.0001$ \\
\hline Position & 72.7131 & 20 & 0.1269 & - & - \\
Error & 2.5386 & - & - & - \\
Total & 75.2517 & 22 & - & -
\end{tabular}

Note: In order to save space, other equations' regression analysis tables are omitted and all rs are $<0.0001$.

it can be seen that four fibers' moisture absorption and desorption rates during the whole course of moisture absorption and desorption were constantly changing. And moisture absorption and desorption rates affect clothes' thermal-wet comfort and the speeds of fibers' moisture absorption and desorption. Therefore, it is necessary to establish moisture absorption and desorption rates' regression curves to master their laws of change. The physical meaning for fibers' moisture absorption and desorption rates is: In standard state, unit-mass fiber's instant absorption or desorption amount can be expressed by formula (8):

$$
\mathrm{V}=\left|\frac{\mathrm{dw}}{\mathrm{dt}}\right|
$$

By referencing to formula (1), regression equation's general formula for fiber's moisture-absorption and moisturedesorption rates can be obtained by

$$
\mathrm{V}_{\mathrm{a}} / \mathrm{V}_{\mathrm{d}}=\left|\mathrm{bce}^{-\mathrm{ct}}\right|
$$

In above formula, $\mathrm{V}_{\mathrm{a}} / \mathrm{V}_{\mathrm{d}}$ are moisture-absorption and moisture-desorption rates $\mathrm{g} / \mathrm{min}^{-1}$; both $\mathrm{b}$ and $\mathrm{c}$ are constants. According to formulae (2-7), the regression formulae for four fibers' moisture-absorption and moisture-desorption rates can be obtained:

$$
\begin{aligned}
& \mathrm{V}_{\mathrm{a}(\text { Pineapple-fiber })}=3.8974 \mathrm{e}^{-0.1861 \mathrm{t}} \\
& \mathrm{V}_{\mathrm{d}(\text { Pineapple-fiber })}=0.5814 \mathrm{e}^{-0.0799 \mathrm{t}} \\
& \mathrm{V}_{\mathrm{a}(\text { Flax-fiber })}=3.7715 \mathrm{e}^{-0.1912 \mathrm{t}} \\
& \mathrm{V}_{\mathrm{d}(\text { Flax-fiber })}=0.4690 \mathrm{e}^{-0.0848 \mathrm{t}} \\
& \mathrm{V}_{\mathrm{a}(\text { Ramie-fiber })}=3.5951 \mathrm{e}^{-0.1933 \mathrm{t}} \\
& \mathrm{V}_{\mathrm{d}(\text { Ramie-fiber })}=0.4008 \mathrm{e}^{-0.0808 \mathrm{t}} \\
& \mathrm{V}_{\mathrm{a}(\text { Cotton-fiber })}=2.8535 \mathrm{e}^{-0.1718 \mathrm{t}} \\
& \mathrm{V}_{\mathrm{d}(\text { Cotton-fiber })}=0.2694 \mathrm{e}^{-0.0642 \mathrm{t}}
\end{aligned}
$$

The regression curves for pineapple leaf fiber, flax fiber, ramie fiber and cotton fiber's moisture absorption and moisture desorption rates were plotted according to the regression formulae for moisture absorption and moisture desorption rates. It can be seen from Fig. 4 (a) and (b) that the four fibers' moisture absorption and moisture desorption rates were constantly changing during the whole moisture absorption and moisture desorption processes. During the processes' initial stages, fibers' moisture absorption and moisture desorption rates were the highest. Fibers' moisture contents were con- 


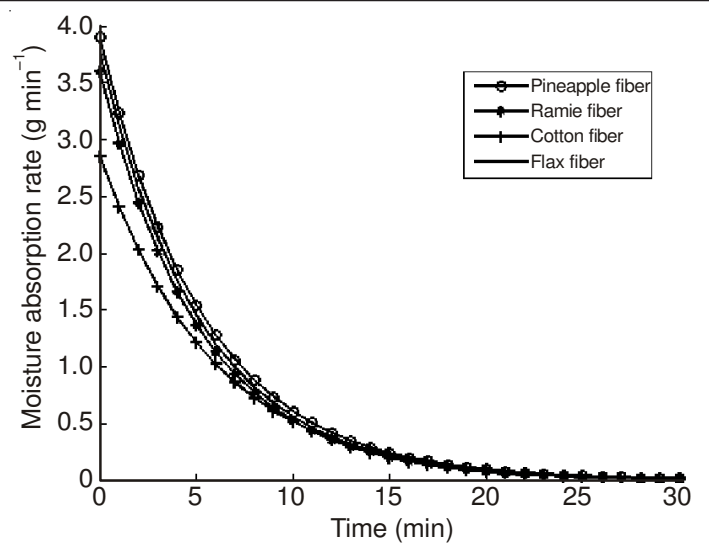

(a) Moisture absorption rate

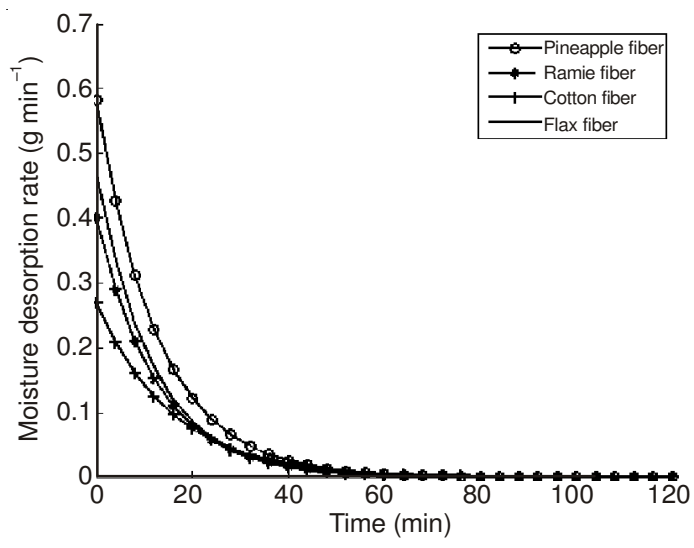

(b) Moisture desorption rate

Fig. 4. Regression curves for moisture absorption and moisture desorption rates

stantly increasing or decreasing with time and their moisture absorption and moisture desorption rates attenuated exponentially. After moisture absorption equilibrium and desorption equilibrium were reached, their moisture absorption and moisture desorption rates declined to the lowest and finally approached zero. Four plant fibers' moisture-absorption rate curves are presented in Fig. 4(a). During moisture absorption process' initial stage, pineapple leaf fiber's moisture-absorption rate was the highest and then its curve overlaps with flax fiber, ramie fiber and cotton fiber's moisture absorption rate curves at around $20 \mathrm{~min}$ position. As time passed, fiber's moisture absorption rate declined and approached zero after $0.5 \mathrm{~h}$ and moisture absorption equilibrium was reached. Four plant fibers' moisture desorption rate curves are shown in Fig. 4(b). During moisture desorption process' initial stage, pineapple leaf fiber's moisture-desorption rate was the highest, followed by flax fiber's and then ramie fiber's and cotton fiber's was the lowest. After $1 \mathrm{~h}$, fiber's moisture desorption rate declined and approached zero first at around 80-minute position. Formation of the above phenomenon has something to do with these four fibers' internal structures. Pineapple leaf fiber, flax fiber, ramie fiber and cotton fiber are all cellulose fibers with the same chemical structures and strong hydrophilic groups. But the fact that their morphologies, aggregate structures, fiber concomitantors or impurities are slightly different caused four plant fibers' moisture-absorption discrepancies.
Fibers' morphological structures: The similarity in pineapple leaf fiber, flax fiber, ramie fiber and cotton fiber's cross-sectional morphologies was observed that all these fibers had lumens; the differences in them were that pineapple leaf fiber had thicker cell walls, was a kind of single-fiber morphology and looked polygonal, while the other three fibers had thinner cell walls, showed a single-fiber morphology and looked waist-round. Pineapple leaf fiber's surface morphology was the same as flax fiber's and ramie fiber's without any natural distortion like cotton fiber's. But, pineapple leaf fiber had rough surface and longitudinal cracks, while flax fiber, ramie fiber and cotton fiber had smoother surfaces. Due to the fact that pineapple leaf fiber's most cross sections were polygonal and have rough surface morphology and cracks, its specific surface area was larger than the other three fibers'. The larger the fiber's specific surface area is, the greater the moisture absorption ability is ${ }^{13}$. Pineapple leaf fiber had larger specific surface area and higher surface adsorption ability and its absorption power was higher than the other three fibers', so its moisture absorption rate was the fastest in the initial stage of the moisture absorption. During moisture desorption, capillary phenomenon happened with the pineapple leaf fiber's surface due to cracks and microgrooves and capillaries enabled moisture in fibers to be conveyed, diffused and volatilized rapidly and therefore water molecules absorbed were discharged to outer layers and evaporated quickly ${ }^{14}$. So, pineapple leaf fiber's moisture desorption rate was the fastest among the four fibers.

Fibers' aggregate structures: Low-crystallinity fibers have bigger amorphous areas and their moisture absorptions occur mainly in amorphous areas ${ }^{11-13}$. Pineapple leaf fiber, flax fiber and ramie fiber's crystallinities were found 70.63, 67.43 and $72.02 \%$, respectively with a crystallinity difference of only $\pm 3 \%$. Their amorphous areas were almost the same size as moisture absorption areas, so pineapple leaf fiber, flax fiber and ramie fiber's moisture-regain rates were smaller which are all only $\pm 0.5 \%$.

Fibers' concomitantors or impurities: Pineapple leaf fiber and flax fiber were processed by semi-degumming technology, so some residual gum was kept in the processed fiber. Natural fiber which is kept with some impurities usually has better moisture absorption performance, so moisture regain rate is affected to some extent ${ }^{13-15}$. Pineapple leaf fiber and flax fiber's moisture regain rates after moisture desorption equilibrium were higher than those of ramie fiber and cotton fiber.

\section{Conclusion}

- Pineapple leaf fiber's cross-section morphology was seen polygonal and the other three fibers' waist-round. Pineapple leaf fiber's surface was observed rough with cracks and the other three fibers' are smooth without cracks. Pineapple leaf fiber's crystallinity was close to flax fiber's and ramie fiber's but higher than that of cotton fiber.

- Pineapple leaf fiber, flax fiber, ramie fiber and cotton fiber's moisture regain rates after moisture absorption equilibrium were $16.04,16.59,16.16$ and $13.33 \%$, respectively, their moisture regain rates after moisture desorption equilibrium were $19.64,19.53,17.92$ and $14.95 \%$, respectively and their moisture-absorption lag values were 3.60, 2.90, 1.76 and $2.90 \%$, respectively. 
- Pineapple leaf fiber's moisture absorption rate was similar to flax fiber's and ramie fiber's and cotton fiber's moisture absorption rate was the lowest. With the pass of time, fibers' moisture absorption rates attenuate exponentially. After $0.5 \mathrm{~h}$, fibers' moisture absorption rate curves approach zero one after another; after $2 \mathrm{~h}$, moisture-absorption equilibrium was reached.

- Pineapple leaf fiber's moisture desorption rate was the highest, followed by flax fiber and ramie fiber and cotton fiber's was the lowest. With the pass of time, fibers' moisture desorption rates attenuated quickly. After $80 \mathrm{~min}$, fibers' moisture desorption rate curves approached zero.

- Pineapple leaf fiber had better moisture absorption performance and its moisture regain rate after moisture-absorption equilibrium and moisture absorption rate were close to flax fiber's and ramie fiber's; its moisture regain rate after moisture-desorption equilibrium and moisture desorption rate were higher than flax fiber's and ramie fiber's. Among the four fibers, cotton fiber's moisture absorption performance was the worst.

\section{ACKNOWLEDGEMENTS}

This work was financially supported by Special Fund for Agro-scientific Research in the Public Interest (201203072); Zhanjiang city science and technology project (2012C0103); Special fund for Basic Scientific Research Business of Central Public Research Institutes (1630012011014).

\section{REFERENCES}

1. C.W. Yu, Y.M. Zhang and F.C. Jiang, China's Fiber Crops, 3, 28 (2000).

2. F. Munder, C. Furll and H. Hempel, in eds.: A.K. Mohanty, M. Misra and L.T. Drzal, Processing of Best Fiber Plants for Industrial Application, Natural Fibers, Biopolymers and Biocomposites, Taylor \& Francis, FL, Boca Raton (2005).

3. L.Y. Mwaikambo, Afr. J. Sci. Technol., 7, 120 (2006).

4. M. Munirah, A.R. Rahmat and A. Hassan, Characterization and Treatment of Pineapple Leaf Fibre Thermoplastic Composite for Construction Application, Research Report, Department of Polymer Engineering, Faculty Chemical and Faculty Natural Resources, Universiti Teknologi Malaysia, pp. 1-63 (2007).

5. W. Hong and S.Y. Xing, China Textile Leader, 3, 52 (2010).

6. A.K. Izgorodin, Y.V. Konoplev, A.G. Zakharov, A.N. Prusov, M.I. Voronova and I. Volkova, Fibre Chem., 36, 343 (2004).

7. J.Z. Zhu, Y.H. Su, H.X. Mao and G.S. Yan, J. Tianjin Polytechnic Univ., 8, 29 (2010).

8. T. Huang, J.R. Jiang, J.L. Wang, W.W. Lian, J. Zhang and Z.G. Deng, Shanghai Textile Sci. Technol., 10, 9 (2009).

9. G.J. Du, X.L. Liu, X.Q. Zheng et al, J. Textile Res., 12, 12 (2008).

10. D. Zhaofang and H. Furong, J. Textile Res., 5, 57 (2012).

11. G.R. Nair, A. Singh, M. Zimniewska and V. Raghavan, Fibers, 1, 59 (2013).

12. G. Lu, Y. Wang, G. Wang, H.-T. Cheng, G.L. Tian and X.-S. Gao, Shanghai Textile Sci. Technol., 9, 9 (2009).

13. Y. Mu, Z. Jinfang and H. Shuzhen, Textile Materials Science, China Textile Press, Beijing, edn. 2, pp. 322-354 (2000).

14. Z. Jinzhong, S. Yumei and M. Huixian, J. Tianjin Polytechnic Univ., 4, 29 (2010).

15. L. Xi, Guangxi Textile Sci. Technol., 3, 38 (2003). 